\title{
Tuber melanosporum spread within sub-optimal climatic zones is controlled by fruiting triggers and not mycorrhiza survival
}

\author{
Paul William Thomas* \\ Mycorrhizal Systems Ltd, Unit 4A, Edge Lane, HX7 7PG. United Kingdom
}

\section{Abstract}

Tuber melanosporum is the most valuable of all cultivatable truffle species. Farming of this species spans every continent with the exception of Antarctica. Tuber aestivum (syn. T. uncinatum) and Tuber brumale are truffle species that have similar host plant preference and a similar affinity for calcareous soils as T. melanosporum, but occur over a broader geographic zone. The geographic limit of T. melanosporum is thought to be climatically dictated but it is not known whether this is due to an impact on mycorrhizal survival or climatically-derived fruiting triggers. Here, data is compiled from five cultivated research sites in the climatically sub-optimal conditions of the UK in order to address this question. Here we show:

(i) Tuber melanosporum mycorrhiza can survive and grow in sub-optimal climatic conditions.

(ii) It is climatically-derived fruiting triggers and not ectomycorrhiza survival that dictate the climatic preferences and geographic spread of T. melanosporum.

(iii) Important climatic parameters for potential fruiting triggers are sunshine hours, summer rainfall and summer temperatures.

The data presented here not only aid our understanding of the ecological parameters of T. melanosporum but also have a practical application for truffle cultivators in choosing suitable locations for a plantation.

Keywords: climate; mycorrhiza abundance; ascocarp; fungal ecology; truffle; hypogeous fungi; ectomycorrhizal fungi

\footnotetext{
*Email: paul@plantationsystems.com
}

Handling Editor: Maria Rudawska 


\section{Introduction}

Hypogeous fungi belonging to the genus Tuber (truffles) are some of the most expensive of all edible fungi, with prices for some species often exceeding thousands of Euros per kilo. A number of truffle species, being obligate mycorrhizal organisms, can be cultivated by inoculating the roots of host trees and planting these into prepared field sites. The most expensive of the cultivatable truffle species is T. melanosporum, currently commanding prices of $1100 \mathrm{EUR} / \mathrm{kg}$ on wholesale markets [1]. France once had large natural population of this species, with several thousand tonnes being harvested at the turn of the last century [2]. However, natural production plummeted, caused by a number of factors such as habitat destruction and potentially also climate change, leading to an increased frequency of drought events [3]. Cultivation of this species was needed to maintain some degree of production and this has been so successful that over $95 \%$ of all T. melanosporum harvested in France now comes from cultivation. Production has spread, encompassing not only countries that have a natural population of this species but also a broad range of other countries. Production in countries that do not have a natural history of T. melanosporum populations has been successful in areas that have a similar climatic profile to natural-producing regions, but interestingly it has also been successful in areas that have significantly different climatic parameters. As such, production in these new regions has increased our understanding of the suitable climatic parameters for cultivation [4]. Thomas [4] showed that despite the black truffle, T. melanosporum, being viewed as occupying a very distinct and rigid environmental niche (after Delmas [5]), the compiled data from sites where T. melanosporum is fruiting in either a natural environment or farmed setting, displays a remarkable degree of climatic variation. Further, the degree of this variation is largely a product not of the natural fruiting extent of T. melanosporum, but of production in areas where this fungus has previously not occurred. We now know that fruiting can be successful in regions with significantly higher rainfall levels or significantly lower summer temperatures than those experienced in the natural range of this species. Two examples are the successful fruiting in the high winter rainfall area of Corvallis, USA [6] and the low summer temperature region of Los Ríos, Chile [7].

Although cultivation in areas that do not have a natural T. melanosporum population has significantly broadened the parameters that we know to be suitable for production, there remains very little data on what happens outside of these parameters. The expansion of parameters is significant, but still the range is relatively constricted when looking at the existing climatic variation in a continent, such as Europe. We do not yet know why, for example, T. melanosporum does not occur in cooler regions of Europe where two other Tuber species, T. aestivum and T. brumale, that have similar host plant preference and an affinity for calcareous soils, can be found [8,9]. Ectomycorrhizal fungi have been shown to be variable in their tolerance to cool temperatures, with some unable to survive freezing temperatures [10]. In order for mycorrhiza to survive freezing temperatures, protective compounds must be synthesized and carbohydrates may be important in this regard [11]. It is clear that mycorrhizal survival may be important in dictating the climatic suitability of a region for T. melanosporum cultivation or survival. However, other data indicate that climatically-derived fruiting triggers are important in influencing climatic preferences for this species. For example, ascocarp production in natural stands is reduced as a dense canopy develops, leading to the assumption that climatic factors influencing irradiance 
and soil temperature may be important fruiting triggers [12]. In the absence of suitable climatically-derived fruiting triggers, ascocarps may not be produced. It is clear that either the survival of mycorrhiza, a lack of suitable climatic-triggers for ascocarp production or a combination of both factors may control suitability of a site.

The classical view of a suitable climate for T. melanosporum production is a relatively conservative range of parameters from southwest (SW) France [5]. SW France is categorized as a Mediterranean climate whereas the UK is temperate. As such, the UK may be considered climatically sub-optimal for T. melanosporum cultivation or survival. Here, using a recently compiled data set from orchards producing ascocarps, spanning six continents, the climate of the UK sites is investigated in order to identify what are the exact climatic parameters that make the UK sub-optimal for T. melanosporum cultivation or survival. Within these climatically diverse UK sites, the survivorship of T. melanosporum mycorrhiza is recorded and then correlated with a range of climatic variables. These correlational analyses will allow us to understand if mycorrhiza survival is a factor dictating climatic suitability for production. Based on the natural range of T. melanosporum, it is often assumed that irradiance and temperature are two of the primary climatic restraints in cultivation. It is therefore hypothesised that these parameters will also be the key constraints in the investigated sub-optimal regions. The data presented here has a practical application for truffle cultivators in choosing suitable locations for a plantation and furthers our understanding of the climatologically influenced boundaries of T. melanosporum.

\section{Material and methods}

\section{UK study sites and mycorrhiza analysis}

A total of five UK sites, planted with T. melanosporum inoculated host trees, were used in this study. The sites were located in different geographic areas with three in the county of Devon, one in Leicestershire and one in Monmouthshire. Host tree species were Quercus ilex, Q. robur and Corylus avellana. The impact of the T. melanosporum mycorrhiza was evident on the vegetation around the base of some host trees, as displayed in Fig. 1. All sites underwent soil aeration and liming to elevate $\mathrm{pH}$ levels to 7.6-7.9 prior to plantation establishment.

From all sites, an average of five trees were sampled. Tree root samples of $4-5 \mathrm{~cm}$ length were removed at a depth of $2-10 \mathrm{~cm}$ in the soil profile during the leaf dormant season of Q. robur and C. avellana. Samples were collected from randomly selected trees within the plantation, with one root sample per tree and placed into plastic samples bags to be transported to the laboratory. Once at the laboratory, root samples were placed into receptacles containing purified water and examined microscopically. Within each sample, the number of root tips that were colonized with T. melanosporum were counted and calculated as a percentage of total root tips observed. The identification of T. melanosporum mycorrhiza was through morphological analysis using published and accepted parameters $[13,14]$. The first sampling occurred 12 months after planting, thereafter annually. Samples were collected between 2010 and 2013. Linear regression was used to check for a relationship between individual climatic parameters and mycorrhization levels. The $r^{2}$ and $P$ values were recorded for each analysis and a result was deemed statistically significant at $P<0.05$. 


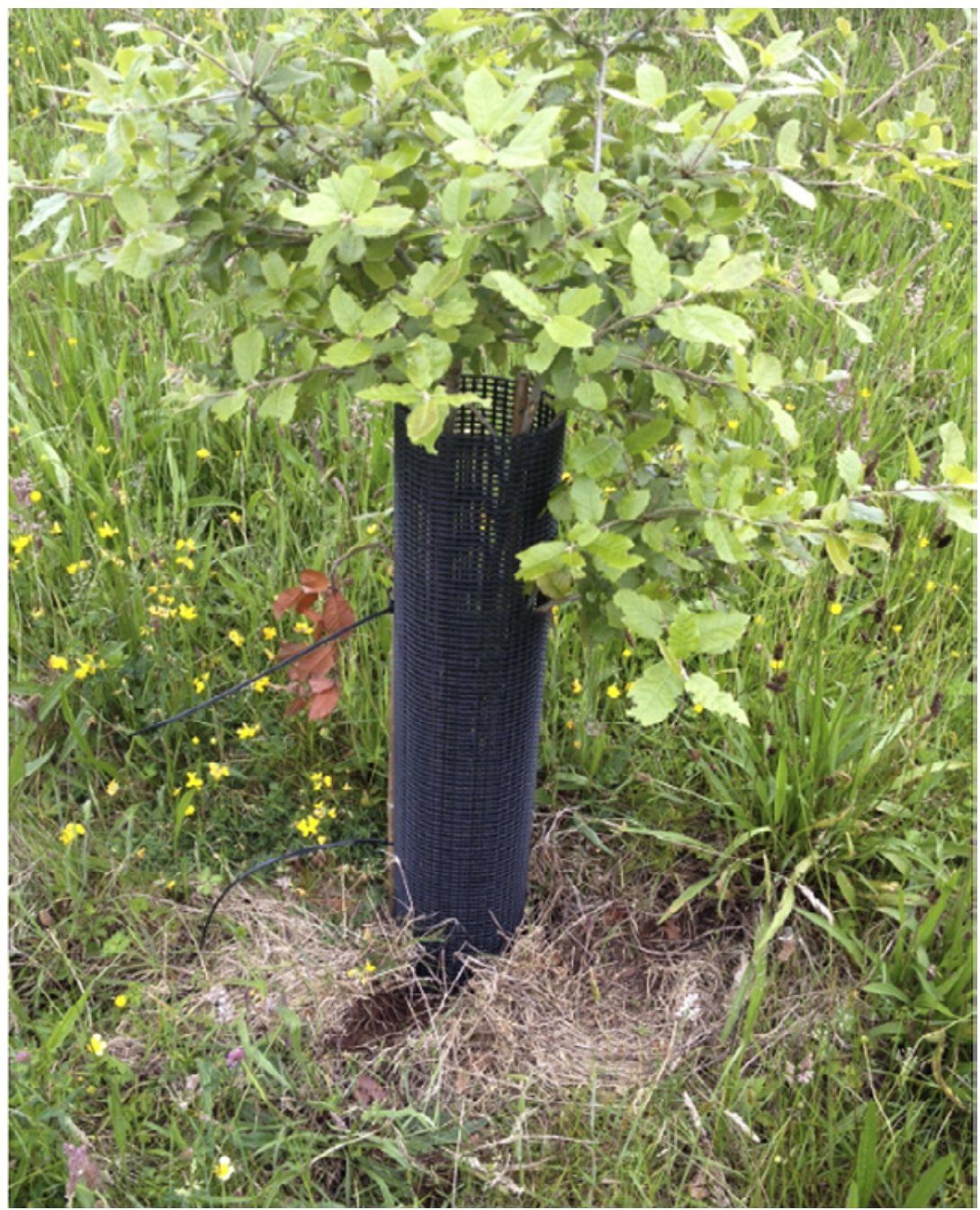

Fig. 1 Quercus ilex host tree from the UK study site in Monmouthshire. The impact of Tuber melanosporum mycorrhiza on the surrounding vegetation is apparent as an area of deceased grassland species.

\section{Climatic analysis}

To assess which climatic parameters of the UK study sites are sub-optimal for T. melanosporum ascocarp production, data was needed on the ideal range of climatic parameters. This data was taken from a recently compiled dataset used by Thomas [4]. Thomas [4] identified published records of ascocarp collection and used the identified locations to present climatic parameters for each individual site. The sites incorporate those from countries that have a historical record of natural T. melanosporum fruiting and those in which T. melanosporum does not occur naturally but is successfully cultivated. Locations 
and represented countries include Spain [15,16], France [17-20], Australia [21,22], Italy [23-25], Canada [6], USA [26], Israel [27], Chile [7], Morocco [28], and New Zealand [29]. Every continent, with the exception of Antarctica, is represented by the data. Summer climate data are taken from the three warmest months of the year. Winter climate data are taken from the three coolest months of the year.

For UK study sites, monthly climatic data for each location was gathered from proximate weather stations, owned and monitored by the Met Office (http://www.metoffice.gov. $\mathrm{uk} /$ ). Summer climate data are taken from the three warmest months of the year. Winter climate data are taken from the three coolest months of the year. Individual unpaired $t$-tests were used to check for a difference in climatic parameters between sites that are producing T. melanosporum ascocarps and UK study sites. Each climatic parameter was tested individually. A $t$-value, degrees of freedom and a $P$-value was recorded for each analysis and a result was deemed statistically significant at $P<0.05$.

\section{Results}

\section{Influence of UK climatic parameters on mycorrhiza abundance}

All climatic parameters of UK study sites displayed variation between sites (Tab. 1). There was a variation in average winter sunshine of 75 hours $(65.3 \%$ of $\max$ ) between the two most extreme sites, a $860 \mathrm{~mm}$ difference in annual rainfall (34\% of max) and a $5.8^{\circ} \mathrm{C}$ difference in mean winter temperatures (18.3\% of max).

Tab. 1 Minimum and maximum figures for climatic variables within UK study sites.

\begin{tabular}{lrrr}
\hline & Minimum & Maximum & Mean \\
\hline Annual temperature & 8.8 & 14.7 & 10.4 \\
Summer temperature & 14.5 & 16.5 & 15.6 \\
Winter temperature & 1.3 & 7.1 & 4.7 \\
Annual sunshine hours & 1421.8 & 1725.0 & 1548.2 \\
Summer sunshine hours & 407.9 & 590.0 & 500.6 \\
Winter sunshine hours & 141.0 & 215.8 & 188.2 \\
Annual rainfall & 450.0 & 1310.3 & 886.7 \\
Summer rainfall & 126.0 & 377.2 & 250.9 \\
Winter rainfall & 97.3 & 318.6 & 211.5 \\
\hline
\end{tabular}

Summer and winter figures are for the three warmest or three coolest months of the year, respectively.

Summer, winter and annual rainfall, temperature and sunshine hours were all analyzed for correlation to mycorrhiza abundance across UK sites (Tab. 2). The only climatic variable to display a correlation with mycorrhiza abundance was winter temperature (Fig. 2), which accounted for $43 \%$ of the variation in mycorrhiza abundance $\left(r^{2}=0.428, P<0.05\right)$. 
Tab. 2 Regression analysis results for a range of climatic variables and mycorrhiza abundance within UK study sites.

\begin{tabular}{lcc}
\hline & $\boldsymbol{r}^{2}$ & $\boldsymbol{P}$ value \\
\hline Annual temperature & 0.062 & $>0.05$ \\
Summer temperature & 0.049 & $>0.05$ \\
Winter temperature $^{*}$ & 0.428 & $<0.05$ \\
Annual sunshine hours & 0.169 & $>0.05$ \\
Summer sunshine hours & 0.005 & $>0.05$ \\
Winter sunshine hours & 0.245 & $>0.05$ \\
Annual rainfall & 0.268 & $>0.05$ \\
Summer rainfall & 0.026 & $>0.05$ \\
Winter rainfall & 0.146 & $>0.05$ \\
\hline
\end{tabular}

* The only variable that shows a statistically significant correlation is winter temperature.

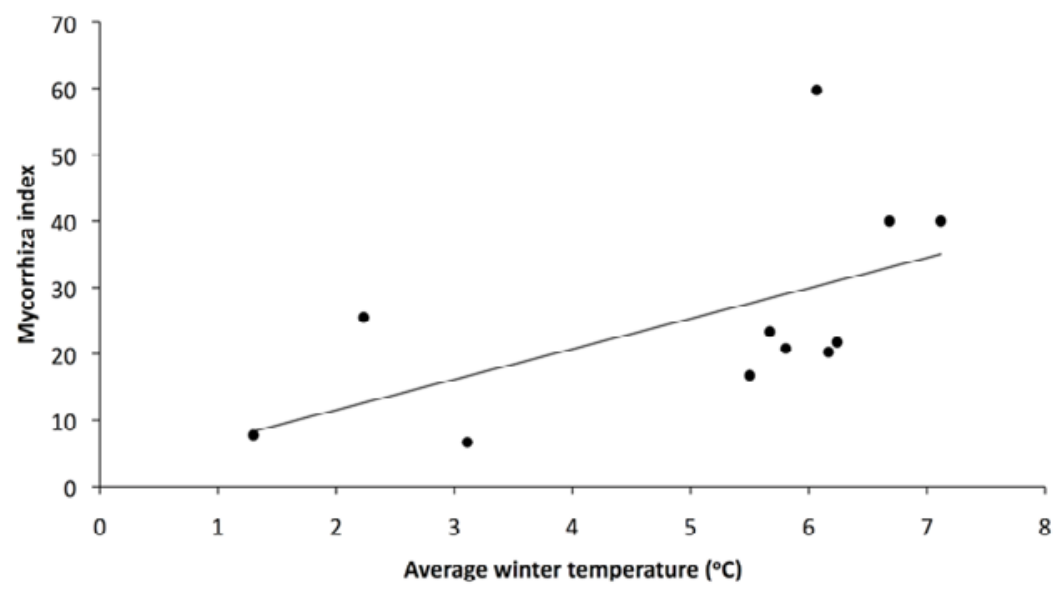

Fig. 2 Mycorrhization of Tuber melanosporum on host plant roots significantly correlated with winter temperature $\left({ }^{\circ} \mathrm{C}\right)$, within UK study sites $\left(r^{2}=0.428, P<0.05\right)$.

\section{Comparison of optimal and suboptimal (UK) climatic parameters}

The recorded annual average temperature was significantly higher $(T=2.295, d f=46$, $P<0.001)$ in sites that are producing T. melanosporum than UK study sites. The average summer temperature of sites that are producing T. melanosporum $\left(21^{\circ} \mathrm{C}\right)$ was also significantly higher than UK study sites $\left(16^{\circ} \mathrm{C} ; T=6.642, d f=46, P<0.001\right.$; Fig. 3a,b). However, there was no significant difference in winter temperature $(T=1.483, d f=46$, $P>0.05$; Fig. 3c). 

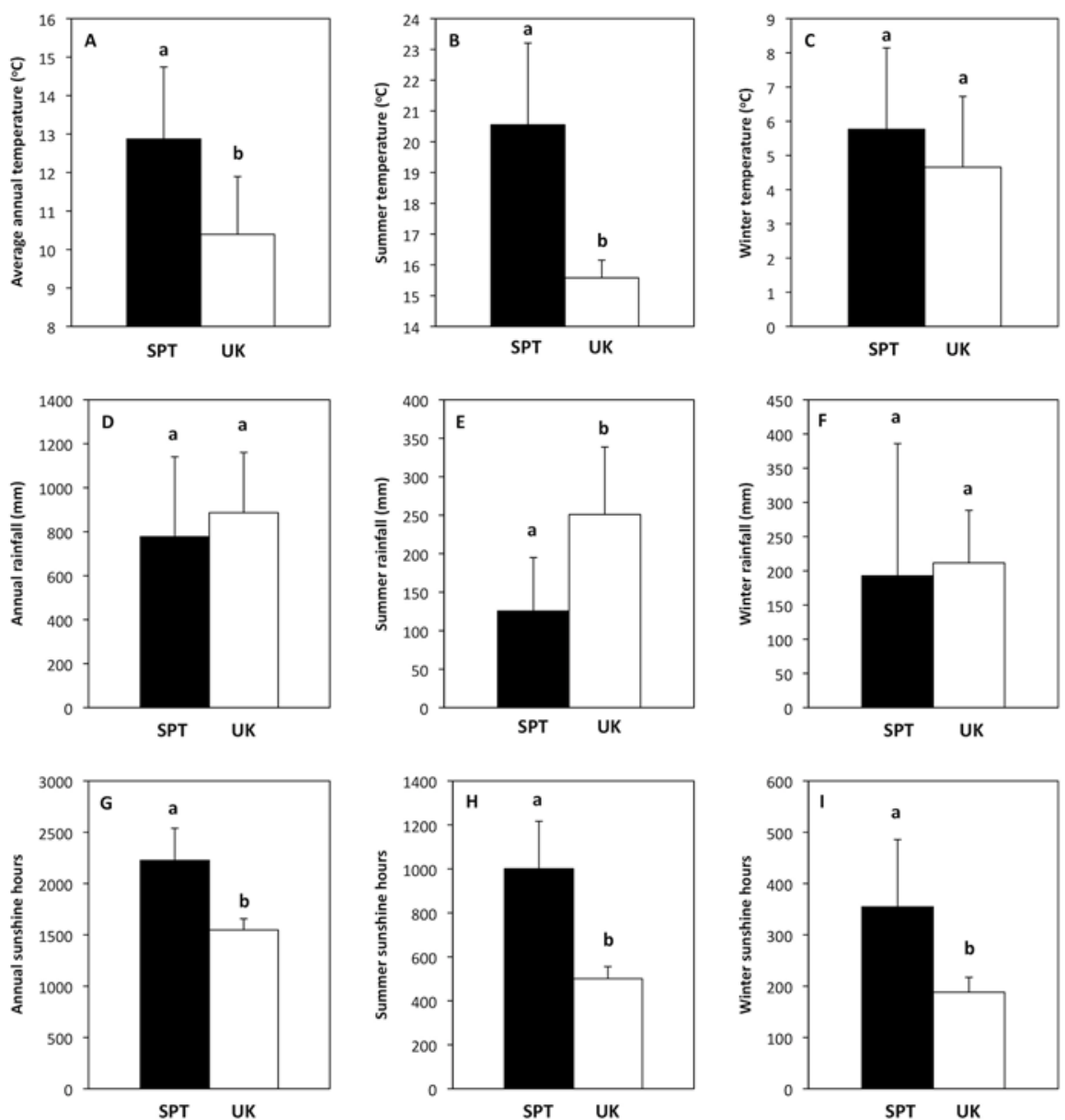

Fig. 3 Mean values $\pm S E$ of average annual temperature $\left({ }^{\circ} \mathrm{C} ; \mathbf{a}\right)$, summer temperature $\left({ }^{\circ} \mathrm{C} ; \mathbf{b}\right)$, winter temperature $\left({ }^{\circ} \mathrm{C} ; \mathbf{c}\right)$, annual rainfall $(\mathrm{mm} ; \mathbf{d})$, summer rainfall $(\mathrm{mm} ; \mathbf{e})$, winter rainfall $(\mathrm{mm} ; \mathbf{f})$, annual sunshine hours $(\mathbf{g})$, summer sunshine hours $(\mathbf{h})$ and winter sunshine hours $(\mathbf{i})$, from sites that are producing Tuber melanosporum ascocarps (SPT) and UK study sites (UK). Error bars are one standard error. Within each graph values followed by different letter codes are significantly different $(t$-test, $P<0.05)$.

There was no significant difference in the annual rainfall $(T=0.954, d f=46, P>0.05)$ or winter rainfall levels $(T=0.339, d f=38, P>0.05)$ between sites that are producing T. melanosporum and UK study sites, but summer rainfall levels were significantly different, with the UK two times higher than $(251 \mathrm{~mm}$ vs. $126 \mathrm{~mm})$ the rainfall of sites that are producing T. melanosporum $(T=4.717, d f=35, P<0.001$; Fig. 3d-f). 
Annual sunshine hours were significantly higher in fruiting sites (2226) than in UK study sites (1548; $T=7.284, d f=42, P<0.001)$. Summer sunshine hours were twice as high in fruiting sites (1001) than in UK study sites $(501 ; T=7.818, d f=28, P<0.001)$ and winter sunshine hours were also significantly higher in fruiting sites than in UK study sites $(T=4.298, d f=21, P<0.001$; Fig. $3 g-\mathrm{i})$.

\section{Discussion}

Tuber melanosporum is an obligate mycorrhizal species and as such its distribution is impacted not only by edaphic factors but also distribution of the host plant range. Cooling events in the Quaternary period, such as the younger Dryas, were so pronounced that some regions in which Tuber species now naturally exist became devoid of host plant species [30]. Host plants and their symbiotic Tuber species survived such periods by retreating to glacial refuges [31]. Tuber melanosporum is similar to two other European native Tuber species, T. aestivum and T. brumale, in terms of host plant preference and an affinity for calcareous, high $\mathrm{pH}$, soils [8,9]. All three Tuber species are also dependent on animal vectors for long distance spore dispersal $[32,33]$. Despite these similarities T. melanosporum has a more restricted range than both T. aestivum and T. brumale, and this is thought to be a factor of climatic preference. This climatic restraint may be dictated by either an inability of the mycorrhiza or mycelium to survive in conditions outside of these parameters or a lack of climatically derived fruiting triggers. Climatic constraints for T. melanosporum combined with the restricted range of dispersal by animal vectors [33] limit the geographic distribution of this species.

Here, for the first time, we have shown that in sub-optimal conditions there is a significant correlation between winter temperature and mycorrhizal colonization of a host plant. This data supports the idea that T. melanosporum has some degree of cold-sensitivity with an associated impact on mycorrhiza survival. Samples used in this study were taken from a relatively shallow depth within the soil profile. At such a position mycorrhiza are exposed to a greater degree of seasonal temperature fluctuation than deeper in the soil profile [34]. Mycorrhization levels at greater depths were not tested and it is possible that these may remain unaffected due to the insulating properties of the deeper soil cover. Further, the winter temperature profile of study sites does not differ significantly from those in which T. melanosporum is known to be fruiting. Therefore, although cooler winter temperatures have a negative impact on mycorrhiza abundance, it cannot be concluded that this climatic parameter alone is a barrier to orchard success or as a restraint on the geographic distribution of this species. Additionally, it should be noted that correlative analysis with parameters such as soil variables and ground cover were not undertaken within this study. Therefore, the potential impact of such variables cannot be discounted.

When the climatic data for the UK study sites were analyzed, it became apparent that the only seasonal climatic variables that displayed significant variation from those of fruiting T. melanosporum sites are sunshine hours, summer temperatures, and summer rainfall. However, none of these variables are correlated with mycorrhization levels within this study. It is perhaps then surprising that T. melanosporum never reached the UK from its refuge during the last glacial expansion, whereas other European Tuber species that require similarly calcareous soils, host plant species and have similar spore 
dispersal methods including T. aestivum and T. brumale, did [8,9,32]. The lack of correlation between mycorrhization levels and the climatic parameters that differ significantly to T. melanosporum producing sites, supports the idea that the climatic restriction on the spread of T. melanosporum to the UK is not acting by an influence on mycorrhiza development. As such, it is concluded that a lack of natural T. melanosporum populations in the UK and areas with a similar sub-optimal climatic profile is a factor of sub-optimal conditions for ascocarp formation and maturation. The initiation of ascocarps generally occurs in the spring and summer months and previous work has suggested that irradiance and soil temperature may be important fruiting triggers [12]. In conjunction with the data presented here, it is suggested that it is summer climactic parameters that are acting as fruiting triggers. Specifically, it is sunshine hours, summer rainfall, summer temperatures or a combination of all three that may prevent the successes of T. melanosporum orchards in sub optimal climatic conditions and are also implicated in the natural spread of this species throughout Europe.

With very few exceptions, cultivation has been concentrated in regions with a very similar climatic profile to that of the natural range of T. melanosporum. Aside from inference from the data collated here, there is very little evidence for the exact climatic boundaries tolerable for successful fruiting of T. melanosporum. Long-term results from the UK sites within this study may shed additional light on these boundaries and further elucidate a role for sunshine hours and summer temperatures.

\section{Acknowledgments}

Thanks to Heather Sutton for her help in processing root samples and assigning climatic data. This study was financed by Mycorrhizal Systems Ltd.

\section{References}

1. Saint Alvare online truffle market [Internet]. 2013 [cited 2013 Dec 12]; Available from: http://www. sainte-alvere.com

2. Courvoisier M. La production et les cours de la truffe d'hiver 1903-1995. Trufficulteur Francais. 1995;10:8-9.

3. Büntgen U, Egli S, Camarero JJ, Fischer EM, Stobbe U, Kauserud H, et al. Drought-induced decline in Mediterranean truffle harvest. Nat Clim Chang. 2012;2(12):827-829. http://dx.doi.org/10.1038/nclimate1733

4. Thomas P. An analysis of the climatic parameters needed for Tuber melanosporum cultivation incorporating data from six continents. Mycosphere. 2014;5(1):137-142.

5. Delmas J. Tuber spp. In: Chang ST, Hayes WA, editors. The Biology and cultivation of edible mushrooms. New York, NY: Academic Press; 1978.

6. B.C.'s first Périgord truffle, worth up to $\$ 2.200$ per kilo, found in Abbotsford [Internet]. Vanc Sun. 2013 [cited 2013 Nov 14]; Available from: http://www.vancouversun.com/life/first+P\%C3\%A9rigord+truffle +worth+kilo+found+Abbotsford/8155234/story.html

7. Cordero C, Cáceres P, González G, Quiroz K, Carmen B, Ramírez R, et al. Molecular tools for rapid and accurate detection of black truffle (Tuber melanosporum Vitt.) in inoculated nursery plants and commercial plantations in Chile. Chil J Agric Res. 2011;71(3):488-494. http://dx.doi.org/10.4067/ S0718-58392011000300022

8. Valverde-Asenjo I, García-Montero LG, Quintana A, Velázquez J. Calcareous amendments to soils to eradicate Tuber brumale from T. melanosporum cultivations: a multivariate statistical approach. Mycorrhiza. 2009;19(3):159-165. http://dx.doi.org/10.1007/s00572-008-0224-z

9. Thomas PW. The role of $\mathrm{pH}$ in Tuber aestivum syn. uncinatum mycorrhiza development within commercial orchards. Acta Mycol. 2012;47(2):161-167. http://dx.doi.org/10.5586/am.2012.019 
10. Corbery Y, Le Tacon F. Storage of ectomycorrhizal fungi by freezing. Ann Sci. 1997;54(2):211-217. http:// dx.doi.org/10.1051/forest:19970208

11. Tibbett M, Sanders FE, Cairney JW. Low-temperature-induced changes in trehalose, mannitol and arabitol associated with enhanced tolerance to freezing in ectomycorrhizal basidiomycetes (Hebeloma spp.). Mycorrhiza. 2002;12(5):249-255. http://dx.doi.org/10.1007/s00572-002-0183-8

12. Garcia-Barreda S, Reyna S. Response of Tuber melanosporum fruiting to canopy opening in a Pinus-Quercus forest. Ecol Eng. 2013;53:54-60. http://dx.doi.org/10.1016/j.ecoleng.2012.12.006

13. Rauscher T, Agerer R. Ektomykorrhizen von Tuber melanosporum, Tuber mesentericum und Tuber rufum (Tuberales) an Corylus avellana. Nova Hedw. 1995;61:281-322.

14. Zambonelli A, Salomoni S, Pisi A. Caratterizzazione anatomo-morfologica delle micorrize di Tuber spp. su Quercus pubescens Willd. Micol Ital. 1993;3:73-90.

15. Parladé J, Varga H, Miguel AM, Sáez R, Pera J. Quantification of extraradical mycelium of Tuber melanosporum in soils from truffle orchards in northern Spain. Mycorrhiza. 2013;23(2):99-106. http://dx.doi. org/10.1007/s00572-012-0454-y

16. Suz LM, Martín MP, Colinas C. Detection of Tuber melanosporum DNA in soil. FEMS Microbiol Lett. 2006;254(2):251-257. http://dx.doi.org/10.1111/j.1574-6968.2005.00029.x

17. Le Tacon F, Zeller B, Plain C, Hossann C, Bréchet C, Robin C. Carbon transfer from the host to Tuber melanosporum mycorrhizas and ascocarps followed using a $13 \mathrm{c}$ pulse-labeling technique. PLoS ONE. 2013;8(5):e64626. http://dx.doi.org/10.1371/journal.pone.0064626

18. Napoli C, Mello A, Borra A, Vizzini A, Sourzat P, Bonfante P. Tuber melanosporum, when dominant, affects fungal dynamics in truffle grounds. New Phytol. 2010;185(1):237-247. http://dx.doi. org/10.1111/j.1469-8137.2009.03053.x

19. Pépinière R. Les Pépinières Robin. Saint-Laurent-du-Cros, France. Brochure. 2004:17-18.

20. Shaw PJA, Lankey K, Jourdan A. Factors affecting yield of Tuber melanosporum in a Quercus ilex plantation in southern France. Mycol Res. 1996;100(10):1176-1178. http://dx.doi.org/10.1016/S0953-7562(96)80177-8

21. Bradshaw BP. Physiological aspects of Corylus avellana associated with the French black truffle fungus Tuber melanosporum and the consequence for commercial production of black truffles in Western Australia [PhD thesis]. Perth: Murdoch University; 2005.

22. Linde CC, Selmes H. Genetic diversity and mating type distribution of Tuber melanosporum and their significance to truffle cultivation in artificially planted truffieres in Australia. Appl Env Microbiol. 2012;78(18):6534-6539. http://dx.doi.org/10.1128/AEM.01558-12

23. Baciarelli-Falini L, Rubini A, Riccioni C, Paolocci F. Morphological and molecular analyses of ectomycorrhizal diversity in a man-made T. melanosporum plantation: description of novel truffle-like morphotypes. Mycorrhiza. 2006;16(7):475-484. http://dx.doi.org/10.1007/s00572-006-0066-5

24. Castrignanò A, Goovaerts P, Lulli L, Bragato G. A geostatistical approach to estimate probability of occurrence of Tuber melanosporum in relation to some soil properties. Geoderma. 2000;98(3-4):95-113. http://dx.doi.org/10.1016/S0016-7061(00)00054-9

25. Lulli L, Bragato G, Gardin L. Occurrence of Tuber melanosporum in relation to soil surface layer properties and soil differentiation. Plant Soil. 1999;214(1-2):85-92. http://dx.doi.org/10.1023/A:1004602519974

26. O'neill M. Coveted, French, and now in Tennessee [Internet]. N.Y. Times. 2007 [cited 2013 Nov 14]; Available from: http://www.nytimes.com/2007/02/28/dining/28truf.html

27. Turgeman T, Sitrit Y, Danai O, Luzzati Y, Bustan A, Roth-Bejerano N, et al. Introduced Tuber aestivum replacing introduced Tuber melanosporum: a case study. Agroforest Syst. 2012;84(3):337-343. http:// dx.doi.org/10.1007/s10457-011-9478-0

28. Khabar L, editor. Ecological and phytosociological study of truffles (genus Tuber) in Morocco. In: The 6th international workshop on edible mycorrhizal mushrooms. April 6-10, 2011. Rabat: Faculty of Sciences Rabat; 2011. p. 60.

29. Hall IR. Taming the truffle: the history, lore, and science of the ultimate mushroom. Portland, OR: Timber Press; 2007.

30. Coope GR, Gibbard PL, Hall AR, Preece RC, Robinson JE, Sutcliffe AJ. Climatic and environmental reconstructions based on fossil assemblages from middle devensian (Weichselian) deposits of the river 
Thames at south kensington, central London, UK. Quat Sci Rev. 1997;16(10):1163-1195. http://dx.doi. org/10.1016/S0277-3791(97)00025-5

31. Murat C, Díez J, Luis P, Delaruelle C, Dupré C, Chevalier G, et al. Polymorphism at the ribosomal DNA ITS and its relation to postglacial re-colonization routes of the Perigord truffle Tuber melanosporum. New Phytol. 2004;164(2):401-411. http://dx.doi.org/10.1111/j.1469-8137.2004.01189.x

32. Luoma DL, Trappe JM, Claridge AW, Jacobs KM, Cazares E. Relationships among fungi and small mammals in forested ecosystems. In: Zabel CJ, Anthony RG, editors. Mammal community dynamics in coniferous forests: management and conservation issues in western North America. New York, NY: Cambridge University Press; 2003. p. 343-373.

33. Piattoni F, Oir F, Morara M, Iotti M, Zambonelli A. The role of wild boars in spore dispersal of hypogeous fungi. Acta Mycol. 2012;47(2):145-153. http://dx.doi.org/10.5586/am.2012.017

34. Pavelka M, Acosta M, Marek MV, Kutsch W, Janous D. Dependence of the $Q_{10}$ values on the depth of the soil temperature measuring point. Plant Soil. 2007;292(1-2):171-179. http://dx.doi.org/10.1007/ s11104-007-9213-9 